\title{
Drug waste minimisation and cost-containment in Medical Oncology: Two-year results of a feasibility study
} Gianpiero Fasola*1, Marianna Aita ${ }^{1}$, Luisa Marini ${ }^{1}$, Alessandro Follador ${ }^{1}$, Marina Tosolini ${ }^{2}$, Laura Mattioni ${ }^{2}$, Mauro Mansutti ${ }^{1}$, Andrea Piga ${ }^{1}$, Silvio Brusaferro ${ }^{3}$ and Giuseppe Aprile ${ }^{1}$

Address: ${ }^{1}$ Department of Medical Oncology, University Hospital of Udine, 33100 Udine, Italy, ${ }^{2}$ Unit of Pharmacy, University Hospital of Udine, 33100 Udine, Italy and ${ }^{3}$ Department of Experimental and Clinical Pathology and Medicine, University Hospital of Udine, 33100 Udine, Italy

Email: Gianpiero Fasola* - fasola.gianpiero@aoud.sanita.fvg.it; Marianna Aita - aita.marianna@aoud.sanita.fvg.it; Luisa Marini - unblast@aoud.sanita.fvg.it; Alessandro Follador - follador.alessandro@aoud.sanita.fvg.it; Marina Tosolini - tosolini.marina@aoud.sanita.fvg.it; Laura Mattioni - mattioni.laura@aoud.sanita.fvg.it; Mauro Mansutti - mansutti.mauro@aoud.sanita.fvg.it; Andrea Piga - piga.andrea@aoud.sanita.fvg.it; Silvio Brusaferro - brusaferro.silvio@aoud.sanita.fvg.it; Giuseppe Aprile - aprile.giuseppe@aoud.sanita.fvg.it

* Corresponding author

Published: I April 2008

BMC Health Services Research 2008, 8:70 doi:10.1 186/1472-6963-8-70
Received: I October 2007

Accepted: I April 2008

This article is available from: http://www.biomedcentral.com/1472-6963/8/70

(c) 2008 Fasola et al; licensee BioMed Central Ltd.

This is an Open Access article distributed under the terms of the Creative Commons Attribution License (http://creativecommons.org/licenses/by/2.0), which permits unrestricted use, distribution, and reproduction in any medium, provided the original work is properly cited.

\section{Abstract}

Background: Cost-containment strategies are required to face the challenge of rising drug expenditures in Oncology. Drug wastage leads to economic loss, but little is known about the size of the problem in this field.

Methods: Starting January 2005 we introduced a day-to-day monitoring of drug wastage and an accurate assessment of its costs. An internal protocol for waste minimisation was developed, consisting of four corrective measures: I. A rational, per pathology distribution of chemotherapy sessions over the week. 2. The use of multi-dose vials. 3. A reasonable rounding of drug dosages. 4. The selection of the most convenient vial size, depending on drug unit pricing.

Results: Baseline analysis focused on 29 drugs over one year. Considering their unit price and waste amount, a major impact on expense was found to be attributable to six drugs: cetuximab, docetaxel, gemcitabine, oxaliplatin, pemetrexed and trastuzumab. The economic loss due to their waste equaled $4.8 \%$ of the annual drug expenditure. After the study protocol was started, the expense due to unused drugs showed a meaningful 45\% reduction throughout 2006.

Conclusion: Our experience confirms the economic relevance of waste minimisation and may represent a feasible model in addressing this issue.

A centralised unit of drug processing, the availability of a computerised physician order entry system and an active involvement of the staff play a key role in allowing waste reduction and a consequent, substantial cost-saving. 


\section{Background}

The past ten years have seen a significant and progressive cost rising in Medical Oncology [1], largely due to the increase in cancer prevalence and the incorporation into clinical practice of novel, highly expensive drugs [2]. Indeed, the formidable bounce of recent scientific progress has led to the development, approval and licensing of novel, both cytotoxic and biological agents; these drugs have shown efficacy in clinical trials, provide further hope to cancer patients but are among the costliest in medical care [1].

The cost of one cycle of chemotherapy may range from $2,500 \$$ for docetaxel $75 \mathrm{mg} / \mathrm{m} 2$ to $4,000 \$$ for pemetrexed $500 \mathrm{mg} / \mathrm{m} 2$, both delivered every three weeks [3]. As for biological agents, one month of treatment costs from 2,300 \$ for erlotinib to more than 4,000 \$ for both trastumuzab and bevacizumab $[1,4]$. Even more expensive is cetuximab, that sells for $8,700 \$$ monthly [1].

Ims Health, provider of consulting services for pharmaceutical and healthcare industries, anticipates that by 2008 antineoplastic drugs will become the top therapeutic area and their market will total over 40 billions USD, an almost 50\% increase as compared with 2004 [5].

Thus, the "oncologic time bomb" predicted in 1999 by an American Cancer Society task force has exploded [2] and the question of how patients and society will afford dramatically rising drug payments remains partly unanswered.

Several strategies have been suggested to this end: from the promotion of an evidence-based medicine to the adoption of validated endpoints both in clinical studies and in the process of drug approval [6]; from the search of relevant biomarkers for a better identification of responsive patients [7] to a proper allocation of health systems resources toward the fields of disease prevention and early detection [8]. Overall, it seems that comprehensive actions resulting from a thoughtful debate among the oncological community, the government, pharmaceutical industries and health insurers are needed to secure the financial future of health systems. Nonetheless, the formulation of satellite measures, short-run but also zerocost may be highly desirable in such a scenario.

Drug waste may be defined as the consequence of an inappropriate disposal of unused or partially used ampoules, vials, or syringes of drugs [9]. It has been previously demonstrated that inefficiency of drug use and waste production may lead to a distinct economic loss, though experiences are limited and most studies are dated or focus on other therapeutic areas [9-12]. Decreasing waste is an attractive cost-cutting strategy since it neither limits specific drug use nor affects quality of care.

Our Department of Medical Oncology is a research-oriented academic unit, admitting about two thousands new patients every year. Facilities include an eighteen-bed dayhospital service and a fourteen-bed ward. The Clinic hosts a centralised unit for drug preparation and is equipped with a homegrown computerised physician order entry (CPOE) system; these features offer a unique opportunity for a sound management of drug preparation, prescription and administration.

In this framework, a project of drug use surveillance and waste reduction was designed and launched at the end of 2004. The project aimed at:

- monitoring the global amount of CT waste during a oneyear observation period

- estimating the resulting economic loss and the relative influence of each drug

- measuring the cost-saving effect of a number of proposed corrective measures. More specifically, a per pathology/per drug organisation of treatment sessions over the week - in order to allow the re-use of leftovers while respecting drug stability - as well as a reasonable rounding of drug dosages (i.e., within 5\% of calculated dose) [13] were encouraged. Multi-dose vials, that maintain much longer microbial and chemical stability, were used whenever possible, and - depending on drug unit pricing - the most convenient vial sizes were selected for use among available options.

Here we report on first two-year results.

\section{Methods}

\section{5: observation phase}

Since January 2005, the number of dilution cycles for the whole Hospital and for each Department was recorded monthly. Four dedicated laboratory technicians started a day-to-day monitoring of 29 prescription drug order forms, actual use and resulting waste. More specifically, a daily log was manually filled in by individual staff components of the cytotoxic reconstitution unit, who analysed the total amount of each drug prescription and the real amount of consumed drugs, and computed the difference. The Hospital Pharmacy provided a periodical report on the negotiated price per milligram of each observed drug, so that planned and de facto expense could be compared and the economic loss due to waste exactly determined.

Monthly variations in the waste of each drug and possible reasons were recorded. A Web literature search was per- 
formed and different domestic and international realities analysed for matching experiences.

Finally, an internal protocol for waste minimisation could be developed, consisting of four major corrective measures:

- a rational, per pathology/per drug distribution of chemotherapy sessions over the week, in order to allow the reuse of leftovers in other patients on the same or the following day, while respecting both chemical and microbiological drug stability. In particular, a model of organisation was devised and launched, scheduling the CT sessions for gastrointestinal malignancies to take place on Monday and Wednesday, those for thoracic malignancies on Tuesday, and breast cancer treatment sessions on Thursday and Friday

- the choice, whenever possible, of multi-dose vials, that maintain microbial and chemical stability for up to 28 days

- a reasonable rounding of drug dosages (i.e., within 5\% of calculated dose) [13], to fit with available vial sizes/leftovers and avoid the waste of unstable medications

- the selection of the most convenient vial size among different available options, depending on drug unit pricing and on an accurate estimate of the daily actual need of each drug, based on the analysis of validated CPOE prescriptions

\section{6, first semester}

Starting January 2006, the protocol of waste reduction was shared with all staff members and formally adopted. Monthly dilutions, as well as every-day drug prescription and actual consumption continued to be strictly recorded. Possible variations in drug unit pricing were documented.

Drug recovery and resulting money saving were registered monthly for each observed drug. Drug waste cost for the whole year was estimated on the basis of first semester's results and compared with 2005 expenses due to leftovers. Both figures were put in proportion and compared with effective 2005 and estimated 2006 total drug expenditures of the Department, respectively.

A final report was prepared at the end of this period and distributed to all members of the medical staff.

\section{6, last semester}

Starting July 2006, the Authors decided to focus waste minimisation policies and economic analysis on the six drugs that - on the basis of 2005 observations and 2006 first semester's results - appeared to play a primary role from a cost-cutting perspective. In particular, cetuximab, docetaxel, gemcitabine, oxaliplatin, pemetrexed and trastuzumab were selected for analysis. Despite a relatively low drug waste cost during 2005, cetuximab was chosen for two reasons: first, its use was predicted to greatly increase during the following years, as a consequence of marketing approval in Italy in July 2005; second, it was one of the drugs for which a rational allotment of treatment sessions was expected to produce the maximum effect. Although its waste proportion and waste cost were relatively high, topotecan was excluded from further analysis since its occasional use made it a poor candidate for waste recovery. In the same way paclitaxel was not included among "hot drugs", since the introduction of multidose vials from the beginning of the year had allowed to avoid any further drug loss.

In October 2006, an effort was made to improve the practice of dose rounding; indeed, all staff members were provided with a leaflet indicating the most reasonable dose rounding depending on body surface/weight and available vial sizes. Analogous brochures were made available in all Day Hospital offices.

Projected waste cost of the six hot drugs for the whole year and its proportion relative to the overall pharmaceutical expenditure were calculated and compared with both 2005 findings and the initial results (i.e. those of first semester) of waste-containment policies. Finally, 2006 figures were taken all together and compared directly to 2005 observations.

A decrease in negotiated drug prices occurred in this period was taken into account when comparing waste costs of the first vs the last six months of the year; in particular, all estimates were repeated as if prices didn't show any variation. For the same reason, an average price per milligram was used when comparing 2005 vs 2006 figures.

\section{Results}

\section{5: observation phase}

Monthly mean dilutions were 1,102 for the whole Hospital, 633 for the Oncology Unit only.

Waste proportion for all 29 drugs equaled $9.6 \%$ of the total amount of reconstituted drugs, with a net loss of $180,000 €$, corresponding to 6.4 per cent of the Department's annual drug expenditures (Table 1).

Fluctuations in waste proportion appeared to be of different magnitude for different drugs, and median wastage rate showed marked variability as well, ranging from $1.1 \%$ for bleomycin to more than $50 \%$ for topotecan. 
Table I: 2005 baseline evaluation of drug request, drug consuming, waste proportion and correspondent cost

\begin{tabular}{|c|c|c|c|c|c|c|}
\hline Drug & $\begin{array}{c}\text { Total drug } \\
\text { prescribing (mg) }\end{array}$ & $\begin{array}{c}\text { Total drug } \\
\text { consuming (mg) }\end{array}$ & $\begin{array}{c}\text { Waste proportion } \\
(\%)\end{array}$ & $\begin{array}{l}\text { Negotiateda drug } \\
\text { unit pricing ( }(/ \mathrm{mg})\end{array}$ & $\begin{array}{l}\text { Cost of consumed } \\
\text { drugs }(€)\end{array}$ & $\begin{array}{c}\text { Drug waste cost } \\
(€)\end{array}$ \\
\hline Bleomycin & 1735 & 1755 & 1.1 & 1.19 & 2088 & 24 \\
\hline Carboplatin & 115367 & 123380 & 6.5 & 0.082 & 10117 & 657 \\
\hline Cetuximab & 23110 & 24000 & 3.7 & 2.079 & 49896 & 1850 \\
\hline Cyclophosphamide & 834568 & 943265 & 11.5 & 0.005 & 4716 & 543 \\
\hline Cisplatin & 76300 & 83094 & 8.2 & 0.172 & 14292 & 1169 \\
\hline Dacarbazine & 8310 & 10100 & 17.7 & 0.023 & 232 & 41 \\
\hline Docetaxel & 31957 & 33640 & 5.0 & 7.525 & $253|4|$ & 12665 \\
\hline Doxorubicin & 24980 & 26380 & 5.3 & 1.46 & 38515 & 2044 \\
\hline $\begin{array}{l}\text { Liposomial } \\
\text { Doxorubicin }\end{array}$ & 1406 & 1500 & 6.3 & 17.69 & 26535 & 1663 \\
\hline Epirubicin & 64765 & 67160 & 3.6 & 1.907 & 128074 & 4567 \\
\hline Etoposide & 63176 & 72300 & 12.6 & 0.022 & $159 \mid$ & 201 \\
\hline 5-fluorouracil & 5149000 & 5769000 & 10.7 & 0.002 & 11538 & 1240 \\
\hline Fotemustine & 1653 & 2288 & 27.8 & 2.15 & 4919 & 1365 \\
\hline Gemcitabine & 1692015 & 1790600 & 5.5 & 0.142 & 254265 & 13999 \\
\hline Iphosphamide & 43150 & 52000 & 17.0 & 0.014 & 728 & 124 \\
\hline Irinotecan & 95629 & 97690 & 2.1 & 1.76 & 171934 & 3627 \\
\hline Methotrexate & 23531 & 26690 & 11.8 & 0.055 & 1468 & 174 \\
\hline Mitomycin & 273 & 470 & 41.9 & 2.06 & 968 & 406 \\
\hline Mitoxantrone & 134 & 150 & 10.7 & 5.39 & 808 & 86 \\
\hline Oxaliplatin & 84095 & 90050 & 6.7 & 3.71 & 334085 & 22093 \\
\hline Paclitaxel & 120948 & 126502 & 4.4 & 2.376 & 300569 & 13196 \\
\hline Pemetrexed & 36290 & 42500 & 14.6 & 2.54 & 107950 & 15773 \\
\hline Raltitrexed & 36 & 42 & 14.3 & 62.5 & 2625 & 375 \\
\hline Topotecan & 192 & 392 & 51.1 & 64.72 & 25370 & 12944 \\
\hline Trastuzumab & 65003 & 79270 & 17.9 & 4.69 & 371776 & 66912 \\
\hline Vinblastine & 169 & 240 & 29.6 & 0.991 & 238 & 70 \\
\hline Vincristine & 62 & 71 & 12.7 & 2.09 & 148 & 19 \\
\hline Vindesine & 3 & 5 & 40.0 & 20.78 & 104 & 42 \\
\hline Vinorelbine & 13659 & 14530 & 5.9 & 1.96 & 28479 & 1707 \\
\hline TOTAL & 8571516 & 9479064 & 9.6 & & 2147169 & 179576 \\
\hline
\end{tabular}

a2006 official hospital drug prices in Italy are available at [2।]

Waste cost of six compounds only, namely cetuximab, docetaxel, gemcitabine, oxaliplatin, pemetrexed and trastuzumab, accounted for $74 \%(=133,292 €)$ of the total cost of wastes (Table 1) and 4.8 per cent of the Department's annual expenditures (Figure 1). On the other hand, their waste amount was $14 \%$ only of all the waste and their annual wastage rate was generally lower than $10 \%$, with the only exception of pemetrexed and trastuzumab (wastage rate $14.6 \%$ and $18 \%$, respectively).

\section{6, first semester}

Median number of monthly dilutions was consistent with 2005 figures: 1,006 for the whole Hospital, 621 for the Oncology Department. Notably, no variation occurred in drug pricing nor in staff cost.

Following the application of waste containment measures, waste proportion for all drugs decreased from 9.6 to $6.5 \%$, meaning a 41 per cent reduction of the overall waste cost as compared to the previous year and a decrease from 6.4 to $3.1 \%$ with respect to the estimated pharmaceutical expenditure (Table 2).
Corrective measures were successful in reducing the waste proportion of all "hot" drugs, with the only exception of docetaxel, whose leftovers did not show any substantial variation. In particular drug waste for gemcitabine, oxaliplatin and trastuzumab dropped from 5.5 to $2 \%, 6.7$ to $4 \%$ and 17.9 to $7 \%$, respectively (Figure 2 ).

The cost of wastage of the six "hot" compounds decreased from 4.8 to $2.5 \%$ of the overall pharmaceutical expenditure (Figure 1). Indeed, the projected cost of their leftovers for the whole year was estimated to be $85,166 €$ - as compared to $133,292 €$ in 2005 , meaning a planned saving of about 50,000€.

\section{6, last semester}

The last semester of 2006 did not show any substantial variation in drug preparation time and in staff monthly workload: median number of dilutions was 1,159 for the whole Hospital, 710 for the Oncology Unit only. Staff cost was the same as the previous six months.

Starting July, 2006, waste minimisation policies and economic analysis were focused on the six drugs listed in the Methods section. By year's end, the positive trend in waste 


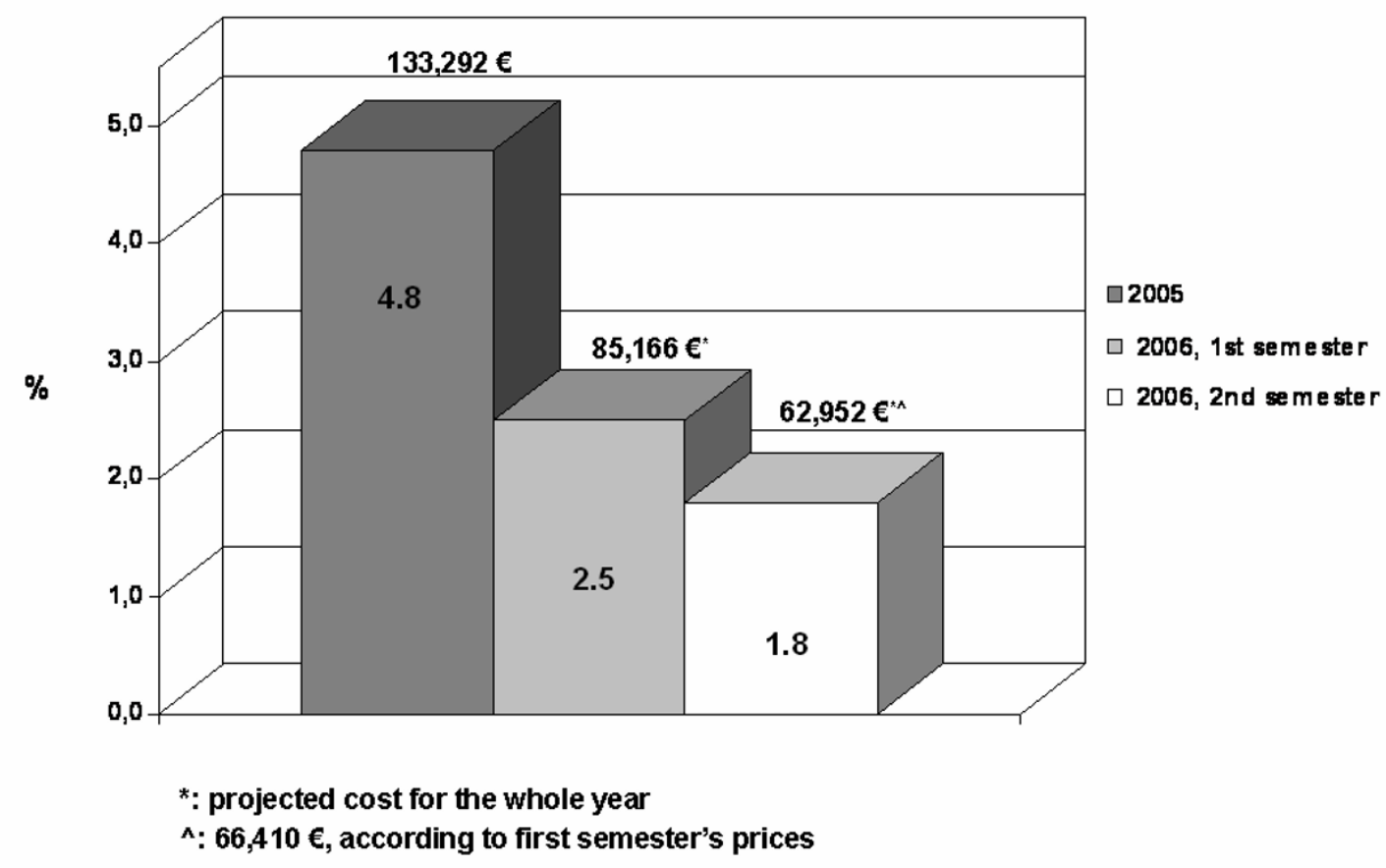

Figure I

Waste cost proportion of "hot" drugs: 2005 vs 2006, first and second semester.

reduction was confirmed, with regard especially to the wastage of gemcitabine, docetaxel, oxaliplatin and trastuzumab, that showed a 75 (from 2 to $0.5 \%$ ), 72 (from 5.3 to 1.5 ), 55 (from 4 to $1.8 \%$ ) and 50 (from 7 to $3.5 \%$ ) per cent further drop, as compared to the first six months (Figure 2). The decrease in the waste rate of pemetrexed was less important, from 13.3 to $12 \%$, while cetuximab inverted its trend, with an increase in wastage rate from 2.8 to $4.9 \%$. Nonetheless the overall projected waste cost further abated from 85,166 to $62,952 €$ (Figure 1), meaning a $26 \%$ absolute reduction and a $28 \%$ reduction of its fraction relative to the pharmaceutical global expenditure, from 2.5 to $1.8 \%$ (Figure 1 ).

The decrease in negotiated drug prices occurred in this period ranged from a minimum of $3 \%$ for trastuzumab to a maximum of $10 \%$ for pemetrexed. When repeating all estimates as if prices had not shown any variation (Table 3 ) we found that drug waste cost for cetixumab, docetaxel, gencitabine, pemetrexed and trastuzumab would have grown of 112, 94, 56, 1,130 and 364 euros, respectively, whereas that of oxaliplatin would have decreased, from 3,329 to 3,302 $€$. Overall, the waste cost of the six drugs would have raised of $1,729 €$ only, meaning a $24 \%$ decrease of its fraction of the overall drug expense, from 2.5 to $1.9 \%$.

\section{Discussion}

In days when mankind's knowledge of cancer is greater than ever before [14] and the number and cost of new anticancer drugs are rising to unexpected heights, overcoming the disproportion between health needs and available resources represents a moral as well as an economic challenge [15].

Unfortunately, most of the strategies that have been proposed to escape the need for health care rationing [16] represent medium-long term solutions, whose impact on high and rising costs is expected to be appreciable in a hardly predictable future. Prompter suggestions are probably needed to control the problem in a short term-oriented manner.

In this perspective, our experience shows how a relatively simple policy of drug waste reduction may significantly decrease their cost impact on the overall pharmaceutical expenditure and allow a substantial cost-saving.

In 2005 a net loss of $180,000 €$, corresponding to 6.4 per cent of the Department's annual expenditures (i.e. $2,800,000 €$ ), could be attributed to futile drug leftovers. Waste cost of six high-priced and/or widely used drugs, i.e. cetuximab, docetaxel, gemcitabine, oxaliplatin, pemetrexed and trastuzumab, accounted for three-quarters of this loss and to 4.8 per cent of the Department's annual 
Table 2: 2006, first semester results

\begin{tabular}{|c|c|c|c|c|c|c|}
\hline Drug & $\begin{array}{c}\text { Total drug } \\
\text { prescribing (mg) }\end{array}$ & $\begin{array}{c}\text { Total drug } \\
\text { consuming (mg) }\end{array}$ & $\begin{array}{c}\text { Waste proportion } \\
(\%)\end{array}$ & $\begin{array}{l}\text { Negotiated a drug } \\
\text { unit pricing ( }(€ / m g)\end{array}$ & $\begin{array}{c}\text { Cost of consumed } \\
\text { drugs }(€)\end{array}$ & $\begin{array}{c}\text { Drug waste cost } \\
(€)\end{array}$ \\
\hline Bleomycin & 0 & 0 & 0 & 1.19 & 0 & 0 \\
\hline Carboplatin & 62975 & 63185 & 0.3 & 0.082 & 5181 & 17 \\
\hline Cetuximab & 47940 & 49300 & 2.8 & 2.079 & 102495 & 2827 \\
\hline Cyclophosphamide & 334314 & 356500 & 6.2 & 0.005 & 1782 & III \\
\hline Cisplatin & 40664 & 42190 & 3.6 & 0.172 & 7257 & 262 \\
\hline Dacarbazine & 42730 & 45700 & 6.5 & 0.023 & $105 \mid$ & 68 \\
\hline Docetaxel & 15630 & 16500 & 5.3 & 7.525 & 124162 & 6547 \\
\hline Doxorubicin & 11532 & 11880 & 3 & 1.46 & 17345 & 508 \\
\hline $\begin{array}{l}\text { Liposomial } \\
\text { Doxorubicin. }\end{array}$ & 960 & 1090 & 12 & 17.69 & 19282 & 2300 \\
\hline Epirubicin & 31350 & 31580 & 0.7 & 1.907 & 60223 & 439 \\
\hline Etoposide & 11855 & 14200 & 16.5 & 0.022 & 312 & 52 \\
\hline 5-fluorouracil & 2769077 & 3019370 & 8.3 & 0.002 & 6039 & 501 \\
\hline Fotemustine & 1000 & 1040 & 3.8 & 2.15 & 2236 & 86 \\
\hline Gemcitabine & 786330 & 802000 & 2 & 0.142 & 113884 & 2225 \\
\hline Iphosphamide & 132050 & 137000 & 3.6 & 0.014 & 1918 & 69 \\
\hline Irinotecan & 47995 & 48695 & 1.4 & 1.76 & 85703 & 1232 \\
\hline Methotrexate & 9118 & 9700 & 6 & 0.055 & 533 & 32 \\
\hline Mitomycin & 196.5 & 250 & 21.4 & 2.06 & 515 & 110 \\
\hline Mitoxantrone & 15 & 20 & 25 & 5.39 & 108 & 27 \\
\hline Oxaliplatin & 47033 & 49000 & 4 & 3.71 & 181790 & 7298 \\
\hline Paclitaxel & 43932 & 43932 & 0 & 2.376 & 104382 & 0 \\
\hline Pemetrexed & 26020 & 30000 & 13.3 & 2.54 & 76200 & 10109 \\
\hline Raltitrexed & 37 & 42 & 11.9 & 62.5 & 2625 & 312 \\
\hline Topotecan & 114 & 168 & 32.2 & 64.72 & 10873 & 3495 \\
\hline Trastuzumab & 38433 & 41328 & 7 & 4.69 & 193828 & 13577 \\
\hline Vinblastine & 25 & 20 & 25 & 0.991 & 20 & 5 \\
\hline Vincristine & 20 & 22 & 9 & 2.09 & 46 & 4 \\
\hline Vindesine & 50.5 & 65 & 22.3 & 20.78 & $135 \mid$ & 301 \\
\hline Vinorelbine & 6718 & 6785 & 0.9 & 1.96 & 13299 & $13 \mid$ \\
\hline TOTAL & 4508114 & 4821562 & 6.5 & & 1134440 & 52645 \\
\hline
\end{tabular}

a2006 official hospital drug prices in Italy are available at [2I]

drug expenditures. A strict monitoring of drug use endorsed to acknowledge: first, that recovery policies would probably not apply to drugs showing minor fluctuations in monthly wastage rates, since low variability implied the existence of a somehow physiologic, thus unrecoverable, loss; second, that main reasons for drug waste were essentially the limited extent of CT medication shelf-life and the narrow availability of a range of vial sizes flexibly matching with possible drug dosages. Adopted corrective measures were the logical consequence of these findings: if drug instability is a basis for drug waste, it is reasonable to use, whenever possible, multi-dose vials, that retain a much longer microbial and chemical stability; and to operate a per pathology/per drug distribution system of chemotherapy sessions over the week, in order to allow the re-use of leftovers in other patients, while respecting drug stability. In the same way, if market available vial sizes are relatively few, it makes sense to round down the drug dose to the closest accessible vial size. Notably, dose-rounding has been considered acceptable to within $5 \%$ of calculated dose, since on the basis of pharmacokinetic and clinical issues this dose adjustment is not expected to have any significant effect on either response or toxicity [13,17-19].
In our work we show how the application of straightforward measures allowed to abate the waste amount of the most expensive antineoplastic drugs, its cost and its proportion of total drug expenditure. In particular, a direct comparison of 2005 figures with 2006 reveals how the overall waste amount for the six "hot" dugs dropped of $66 \%$, its cost decreased of $45 \%$ (from $133,292 €$ to 73,975 $€$, using an average price per milligram) and its fraction of pharmaceutical global expenditure diminished from 4.8 to $2.2 \%$.

Further expenditure cuts may hopefully emerge from other equally feasible solutions. The establishment of an ad hoc policy for recovering unused, unexpired oral antineoplastic drugs (including biological agents) would allow a considerable medication return and money-saving. A concrete cooperation with manufacturing companies should be solicited focusing on ways to improve and validate the stability of drugs, particularly those items that need to be used within hours, and on the production of more suitable final dosage forms (for example, the decrease in pemetrexed wastage rate was less important than for the other hot drugs, since the possibility of drug recovery suffered from the limits imposed by commercially available vial sizes). 


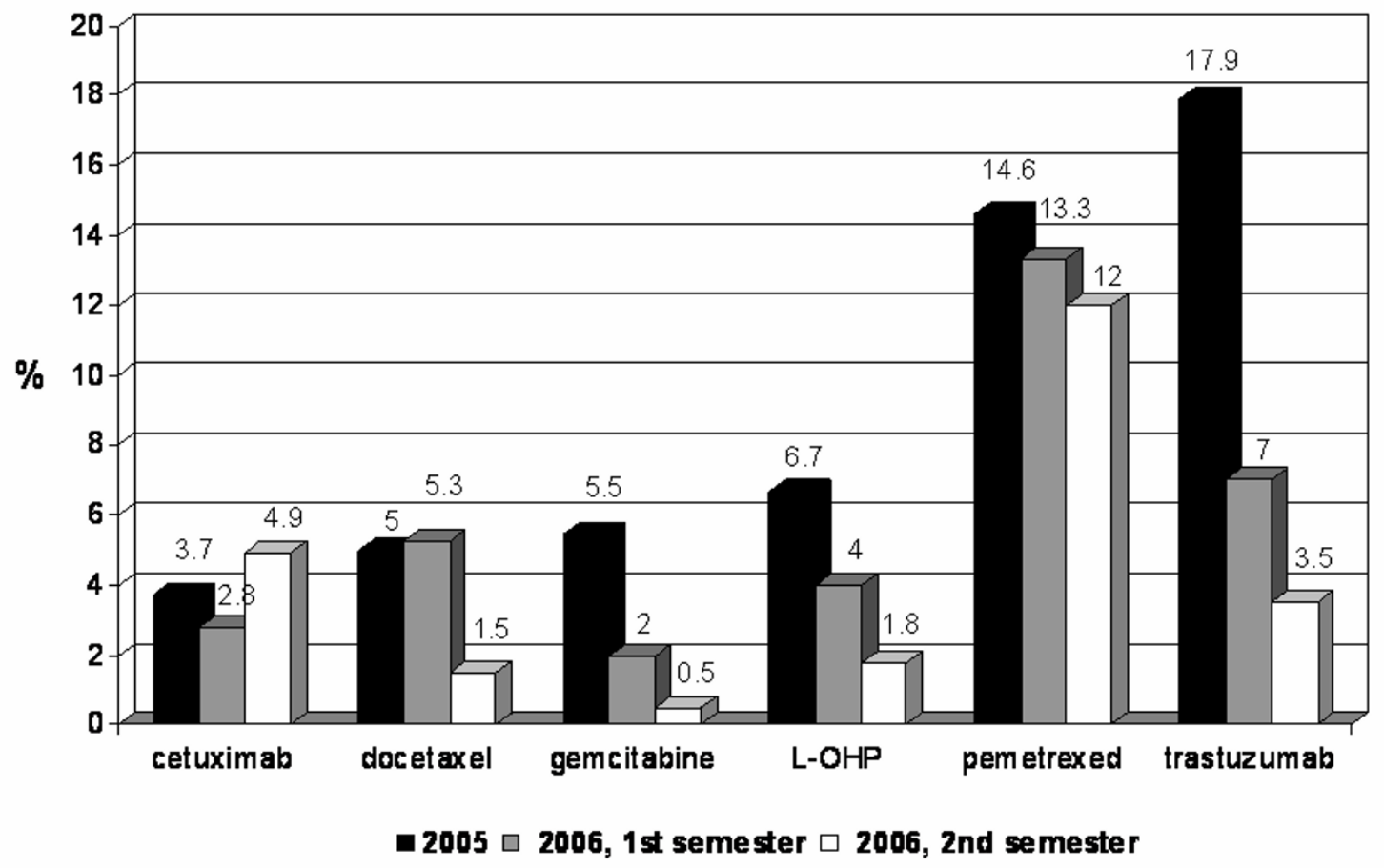

\section{L-OHP: oxaliplatin}

Figure 2

"Hot" drug decrease in waste proportion: 2005 vs 2006, first and second semester.

Our study has some limitations. First, it was conducted at a single centre and its generalisability to settings of different size and with a potentially different mix of diagnoses and disease severity needs to be confirmed.

Second, the rigorous planning of chemotherapy sessions across the week - which plays a key role in waste containment - requires a strictly organised structure and such a policy may be difficult to pursue, especially in the absence of a clinical information system. The increase in cetuxi- mab wastage rate during the second semester of 2006, which was probably due to a demanding 24-hour concentration of chemotherapy sessions for colorectal cancer patients, is an example of such a hindrance. At present, we are working toward the validation and inward testing of drug microbial stability, with the aim of easing the planning and escaping from the needs of a too rigid system.

Finally, it has been previously estimated that potential savings from the reduction of inefficiencies fall short of

Table 3: 2006, second semester results

\begin{tabular}{|c|c|c|c|c|c|c|c|}
\hline Drug & $\begin{array}{c}\text { Total drug } \\
\text { prescribing (mg) }\end{array}$ & $\begin{array}{c}\text { Total drug } \\
\text { consuming (mg) }\end{array}$ & $\begin{array}{c}\text { Waste } \\
\text { proportion (\%) }\end{array}$ & $\begin{array}{l}\text { Negotiateda } \\
\text { drug unit pric- } \\
\text { ing ( }(€ / m g)\end{array}$ & $\begin{array}{l}\text { Cost of } \\
\text { consumed drugs } \\
(€)\end{array}$ & $\begin{array}{c}\text { Drug waste cost } \\
(€)\end{array}$ & $\begin{array}{c}\text { Drug waste cost } \\
\text { according to Ist } \\
\text { semester's prices } \\
(€)\end{array}$ \\
\hline Cetuximab & 31483 & 33100 & 4.9 & 2.01 & 66531 & 3250 & 3362 \\
\hline Docetaxel & 20491 & 20811 & 1.5 & 7.23 & 150463 & 2314 & 2408 \\
\hline Gemcitabine & II32387 & 1138600 & 0.5 & 0.133 & 151434 & 826 & 882 \\
\hline Oxaliplatin & 49370 & 50260 & 1.8 & 3.74 & 187972 & 3329 & 3302 \\
\hline Pemetrexed & 31656 & 36000 & 12 & 2.28 & 82080 & 9904 & 11034 \\
\hline Trastuzumab & 71345 & 73950 & 3.5 & 4.55 & 336472 & 11853 & 12217 \\
\hline TOTAL & 1336732 & $|35272|$ & 1.2 & & 974952 & 31476 & 33205 \\
\hline
\end{tabular}

a2006 official hospital drug prices in Italy are available at [2I] 
administration's cost containment [20]; thus, our strategy may best function as an interim measure, in hold of more comprehensive, long-term plans to achieve sustainable outcomes.

\section{Conclusion}

Our study demonstrates that in Medical Oncology drug waste reduction is feasible and economically convenient. The existence of a centralised unit for drug manufacturing, providing a continuous surveillance on drug prescription and utilisation, a meticulous planning of daily workload, granted by $\mathrm{CPOE}$, and an actively shared information and feedback among staff members are key elements to successfully pursue the proposed strategies.

The concept of "sustainability" should not allude only to the mandate of reducing health care expenditure. A sustainable oncology is economically affordable; at the same time it provides to all the community an equal right to proper levels of physical and mental well-being and aims to ceaseless progress and innovation. In this sense, the identification of easily applicable solutions, that allow to control rising costs while maintaining or improving the quality of patient care, remains challenging but highly attractive.

\section{Abbreviations}

NSCLC: non-small cell lung cancer; i.e.: id est; CT: chemotherapy; USD: United States dollars; CPOE: computerised physician order entry; vs: versus

\section{Competing interests}

The author(s) declare that they have no competing interests.

\section{Authors' contributions}

All authors have substantially contributed to the research. Specifically GF, GA and LM conceived the idea for the study, and, with MA, designed and planned the research. All authors were involved in data collection; MA, LM, AF, MT, LM and MM analysed them. MA wrote the first draft of the manuscript; GF, LM, AP, SB and GA critically revised it. All authors read and approved the final version of the manuscript.

\section{Acknowledgements}

We would like to thank all the staff of our unit for drug preparation, Stefania Casani, Federica Cimolino, Chiara Fantini, Elisa Forgiarini and Erika Glerean, for their contribution to the collection of study data and the implementation of corrective measures. We are also grateful to Raffaela Donato, head nurse of our Day Hospital Unit, for her organisational support.

\section{References}

I. Meropol NJ, Schulman KA: Cost of Cancer Care: Issues and Implications. J Clin Oncol 2007, 25:180-186.
2. Reeder CE, Gordon D: Managing oncology costs. Am J Manag Care 2006, I 2(SuppI I):3-I6.

3. Ramsey SD, Clarke LMS, Kamath TV, Lubeck D: Evaluation of erlotinib in advanced non-small cell lung cancer: impact on the budget of a U.S. health insurance plan. J Manag Care Pharm 2006, 12:472-478.

4. Fleming T: Redbook, 2005 Edition Montvale:Thomson PDR; 2005.

5. IMS Global Insights. World Markets [http:// www.imshealth.com/web/content/

$0,3 \mid 48,64576068 \quad 6387270270260998 \quad 73052844,00 . \mathrm{html}]$

6. Johnson JR, Williams G, Pazdur R: End points and United States Food and Drug Administration approval of oncology drugs. J Clin Oncol 2003, 2 I: | 404- |4| I.

7. Sledge GW: What is targeted therapy? J Clin Oncol 2005, 23:1614-1615.

8. Callahan D: False hopes: overcoming the obstacles to a sustainable, affordable medicine New Brunswick: Rutgers University Press; 1998.

9. Nava-Ocampo AA, Alarcon-Almanza JM, Moyao-Garcýa D, RamírezMora JC, Salmerón J: Undocumented drug utilization and drug waste increase costs of pediatric anesthesia care. Fundam Clin Pharmacol 2004, I8: 107-II2.

10. Diehl LD, Goo EDH, Sumiye L, Ferrell R: Reducing waste of intravenous solutions. Am J Hosp Pharm 1992, 49:106-108.

II. Favier M, Fliche E, Bressolle F: Economic benefit of a centralized reconstitution unit of cytotoxic drugs in isolator. J Oncol Pharm Pract 1996, 2: 182-185.

12. Gillerman RG, Browning RA: Drug use inefficiency: a hidden source of wasted health care dollars. Anesth Analg 2000 , 91:921-924.

13. Dooley MJ, Singh S, Michael M: Implications of dose rounding of chemotherapy to the nearest vial size. Support Care Cancer 2004, I 2:653-656.

14. Apolone G, Joppi R, Bertele V, Garattini S: Ten years of marketing approvals of anticancer drugs in Europe: regulatory policy and guidance documents need to find a balance between different pressures. Br J Cancer 2005, 93:504-509.

15. Nadler E, Eckert B, Neumann P): Do oncologists believe new cancer drugs offer good value? Oncologist 2006, II:90-95.

16. Sulmasy DP: Cancer Care, Money, and the Value of Life: Whose Justice? Which Rationality? J Clin Oncol 2007, 25:217-222

17. Hempel G, Boos J: Flat-fixed dosing versus body surface area based dosing of anticancer drugs: there is a difference. Oncologist 2007, 12:924-926.

18. Moreno-Solórzano I, lbeas-Rollan R, Monzó-Planella M, MorenoSolórzano J, Martínez-Ródenas F, Pou-Sanchis E, Hernández-Borlan R, Navarro-Vigo M, Ortigosa-Rodríguez S, Gel-Moreno B: Two Doses of oxaliplatin with capecitabine (XELOX) in metastatic colorectal cancer. Clin Colorectal Cancer 2007, 6:634-640.

19. Bajetta E, Di Bartolomeo M, Mariani L, Cassata A, Artale S, Frustaci S, Pinotti G, Bonetti A, Carreca I, Biasco G, Bonaglia L, Marini G, lannelli A, Cortinovis D, Ferrario E, Beretta E, Lambiase A, Buzzoni R, Italian Trials in Medical Oncology (I.T.M.O.) Group: Randomized multicenter Phase II trial of two different schedules of irinotecan combined with capecitabine as first-line treatment in metastatic colorectal carcinoma. Cancer 2004, 100:279-287.

20. Schwartz WB, Mendelson DN: Eliminating waste and inefficiency can do little to contain costs. Health Aff (Millwood) 1994 13:224-238.

21. Italian Medicines Agency (AIFA). Official hospital drug prices wscs render attachment by id/ III.84470.1172743348645ce4c.pdf?id=III.81951.11726584903।4]

\section{Pre-publication history}

The pre-publication history for this paper can be accessed here:

http://www.biomedcentral.com/1472-6963/8/70/prepub 